\title{
Tuberculous Duodenal Stenosis: Report of Two Cases
}

\author{
O. Benzekria $\quad$ S. El Mouhadi ${ }^{b} \quad$ M. Chourak $^{a} \quad$ S. Boussetta ${ }^{a}$ \\ M. El Absia M. Echarab M. Elouanani $^{\mathrm{a}} \quad$ M. Amraoui ${ }^{\mathrm{a}}$ \\ A. Errougani ${ }^{\mathrm{a}}$ F.H. El Alami ${ }^{\mathrm{a}}$ R. Chkoffa \\ ${ }^{a}$ Service des Urgences Chirurgicales Viscérales and ${ }^{\mathrm{b}}$ Service de Radiologie \\ Centrale, CHU Ibn Sina, Rabat, Morocco
}

\section{Key Words}

Tuberculosis · Duodenal · Stenosis · Surgery $\cdot$ Complications

\begin{abstract}
Duodenal tuberculosis is a rare clinical entity. The authors report and emphasize the lack of special clinical, radiological and endoscopic signs of duodenal tuberculosis. The diagnosis is affirmed, at laparotomy, out of the findings of peritoneal granulations or histology of lymphatic nodes. We report our experience of two cases of duodenal tuberculosis presenting with proximal intestinal obstruction and review the available literature.
\end{abstract}

\section{Introduction}

Tuberculosis of the upper gastrointestinal tract is rare even in endemic areas [1]. Duodenal involvement is exceptional with only sporadic cases reported in the MEDLINE database $[1,2]$. The authors report two cases of duodenal tuberculosis revealed by stenosis. This report emphasizes the lack of specific clinical, radiological and endoscopic signs of duodenal tuberculosis and highlights the principal therapeutic modalities.

\section{Case Reports}

Case 1

A 60-year-old patient was admitted to the emergency department with severe abdominal pain and vomiting of one month duration, important weight loss $(10 \mathrm{~kg})$ and poor appetite. He had a history of chronic epigastric pain treated by antiacids and $\mathrm{H}_{2}$ blockers without much relief.

Physical examination showed a cachexic and pale patient with dehydration signs. There was no hepatosplenomegaly or palpable mass, but epigastric tenderness was noted at palpation. Biological tests 
revealed hypochromic anemia with a hemoglobin level of $9.5 \mathrm{~g} / \mathrm{dl}$; laboratory investigations also showed hyponatremia of $130 \mathrm{mmol} / \mathrm{l}$. X-ray chest radiography was normal. Upper gastrointestinal endoscopy showed a dilated stomach with food residue and marked narrowing of the first part of duodenum (fig. 1). Exploration of the rest of the duodenum was impossible because of the stenosis. Endoscopic biopsy revealed nonspecific duodenitis.

At operation, an important thickening of the entire wall of the first part of the duodenum was found. It was responsible of an important narrowing of D1 and a dilation of the stomach (fig. 2). Several nodule formations on the serosa, on the peritoneum and tiny ones on the liver surface were observed. There were several enlarged lymph nodes in the mesentery of the small intestine. All these operative findings were suggestive of tuberculosis with involvement of duodenum, liver and peritoneum. A gastroenteroanastomosis was performed. Biopsy from the mesenteric lymph nodes revealed hyperplasia and tubercles with caseation surrounded by epithelioid cells and some Langerhans giant cells.

The following antituberculous treatment was instaured: 2 months of streptomycin, rifampicine, isoniazid and pyrazinamide followed by rifampicine and isoniazid for 9 months. There was a slight improvement in the clinical symptoms.

\section{Case 2}

A 57-year-old male was admitted to our hospital with complaints of vomiting and progressively increasing postprandial epigastric pain of six months duration with significant weight loss $(20 \mathrm{~kg}$ in 6 months). No sign of digestive hemorrhage was noted. He had previously been treated with antiacids and $\mathrm{H}_{2}$ blockers without much relief.

Physical examination was unremarkable. There was no lump in the abdomen. Upper gastrointestinal endoscopy revealed a marked narrowing of the third part of the duodenum. Endoscopic biopsy showed nonspecific duodenitis. Barium examination of the upper gastrointestinal tract revealed stenosis of the third portion of the duodenum associated with a dilated stomach. Abdominal computed tomography (CT) scan showed a $3 \mathrm{~cm}$ stenosis of D3 and a regular thickening of the duodenum walls (fig. 3 , fig. 4 , fig. 5). Routine blood examinations, liver profile and chest radiography were normal.

The patient was subjected to laparotomy for obstruction. Peroperatively, a duodenojejunectomy (D3, D4 and the first jejunal loop) was performed. The second part of the duodenum and the jejunum were anastomosed as a duodenojejunostomy (end to end). The postoperative period was unenventful. Histopathological examination showed an extensive area of caseating necrosis surrounded by epithelioid cells, lymphocytes and giant cells.

The patient was treated with antituberculous chemotherapy for 9 months: streptomycin, rifampicine, isoniazid and pyrazinamide for 2 months followed by rifampicine and isoniazid for 7 months. 3 years subsequently follow-up showed complete recovery from symptoms and $15 \mathrm{~kg}$ weight gain.

\section{Discussion}

Tuberculosis of the gastrointestinal tract most often affects the ileocecal region $[3,4]$. Duodenal involvement accounts for only $2.3 \%$ of tuberculous enteritis [3]. Usually, the intestinal lesions of tuberculosis are associated with other advanced systemic lesions. Isolated forms of intestinal tuberculosis, particularly of the duodenum, are extremely rare. This is probably due to the rapid transit time taken by the gastric contents to travel through the duodenum. The possible routes of infection are directly through mucosa, hematogenous, lymphatic and from adjacent structures in continuity through serosa.

The clinical manifestations of duodenal tuberculosis are varied and nonspecific $[1,5]$. Our patients had features of outlet obstruction. The cause of obstruction can be either stricture or external compression with a reported incidence of 59 and $41 \%$, respectively. Our patients presented with features of upper gastrointestinal tract obstruction and had stricture as the cause of obstruction. 
The radiological features of duodenal tuberculosis are nonspecific $[5,6]$. In our cases barium studies showed a narrowing and irregularity of the duodenal wall. These findings are so unspecific that tuberculosis is almost never considered. Peptic ulcer disease, neoplasm of the duodenum or pancreas, or Crohn's disease is often suspected on that basis [7]. CT has limited value. It may reveal bowel wall thickening and/or lymphadenopathy. Duodenal wall thickening is a nonspecific finding but can suggest the correct diagnosis. Tuberculous lymphadenitis cannot be distinguished from malignant or other lymphadenopathy according to CT criteria. Endoscopic brush cytology and biopsy is only occasionally successful in diagnosis. Submucosal location of the lesion has been cited as a reason for failure of endoscopic biopsies [1].

Due to a lack of accurate clinical diagnosis and radiological features, most patients need surgical intervention for diagnosis $[1,8]$. Patients presenting with diagnostic dilemma or with complications such as a pyloric mass, stenosis, bleeding, or perforation require surgery. However, the laparoscopic approach can be a very interesting tool to diagnose duodenal tuberculosis by permitting biopsies of lymph nodes or peritoneal granulations. This can ovoid surgery in many cases because digestive stenosis can be reversible after specific medical treatment.

The discovery of granulomas in a duodenal stricture, in the absence of caseating lesions, and especially when a sinus tract is present, makes it difficult to distinguish duodenal tuberculosis from Crohn's disease, and may delay proper antituberculous treatment and prompt the unfortunate introduction of a corticotherapy [7]. Surgical intervention is indicated in such cases of duodenal tuberculosis because the obstruction occurs as a result of stricture formation $[4,8]$. The surgical treatement includes either resection of the affected part or a bypass procedure [9]. In our study, we performed in one case a duodenectomy with a duodenojejunal anastomosis, and in the second case a simple gastrojejunostomy. In these cases, both of the two techniques were performed by the same surgeon. Even though we had no postoperative complications and the same functional results in both cases, we believe that the bypass should be preferred because it is simpler to realize. A full course of antitubercular therapy should always complement any operation for duodenal tuberculosis [1-3].

\section{Conclusion}

Duodenal tuberculosis, the rarest form of intestinal tuberculosis, poses great difficulty in diagnosis. Radiologic findings and endoscopic biopsy are nonspecific and surgical intervention is often required to make a diagnosis [2]. Treatment is based on antitubercular therapy; surgery is indicated in case of complication. 


\begin{tabular}{r|l|l|l} 
Case Repports $/ \mathrm{h}$ & $\begin{array}{l}\text { Case Rep Gastroenterol 2008;2:444-450 } \\
\text { D01: 10.1159/000161566 }\end{array}$ & Published online: November 15, 2008 & $\begin{array}{l}\text { 2008 S. Karger AG, Basel } \\
\text { ISSN 1662-0631 } \\
\text { Www.karger.com/crg }\end{array}$ \\
\hline
\end{tabular}

Fig. 1. Barrium study showing an important narrowing of D1.

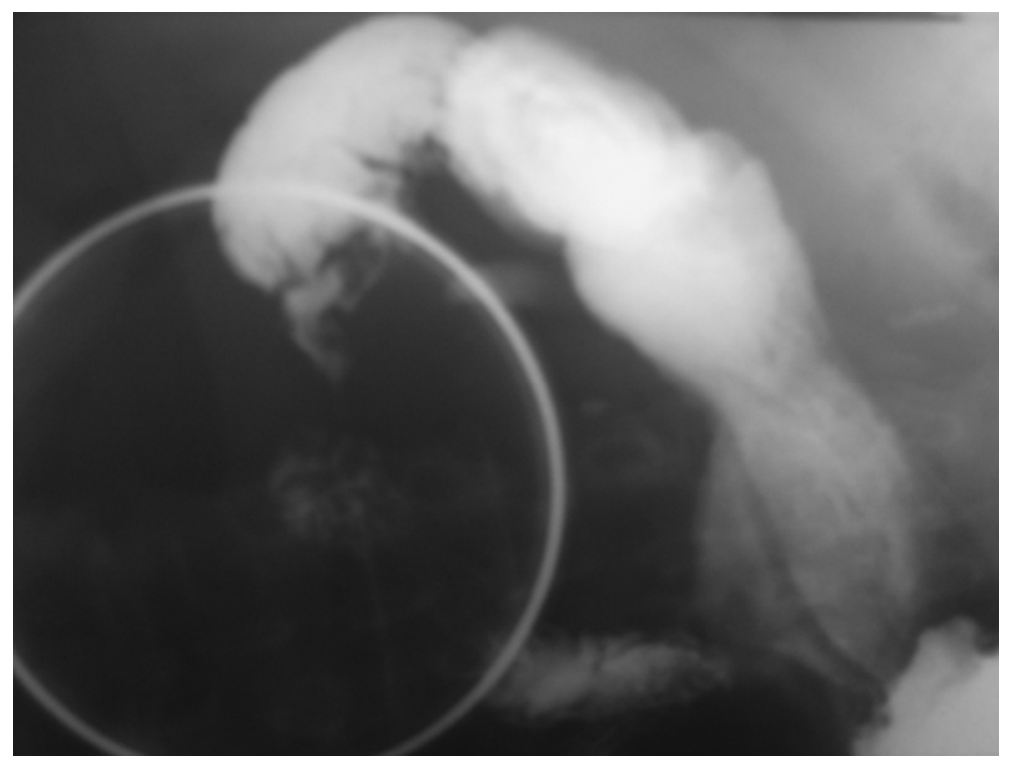

Fig. 2. Peroperative view of duodenal stenosis associated with peritoneal granulations.

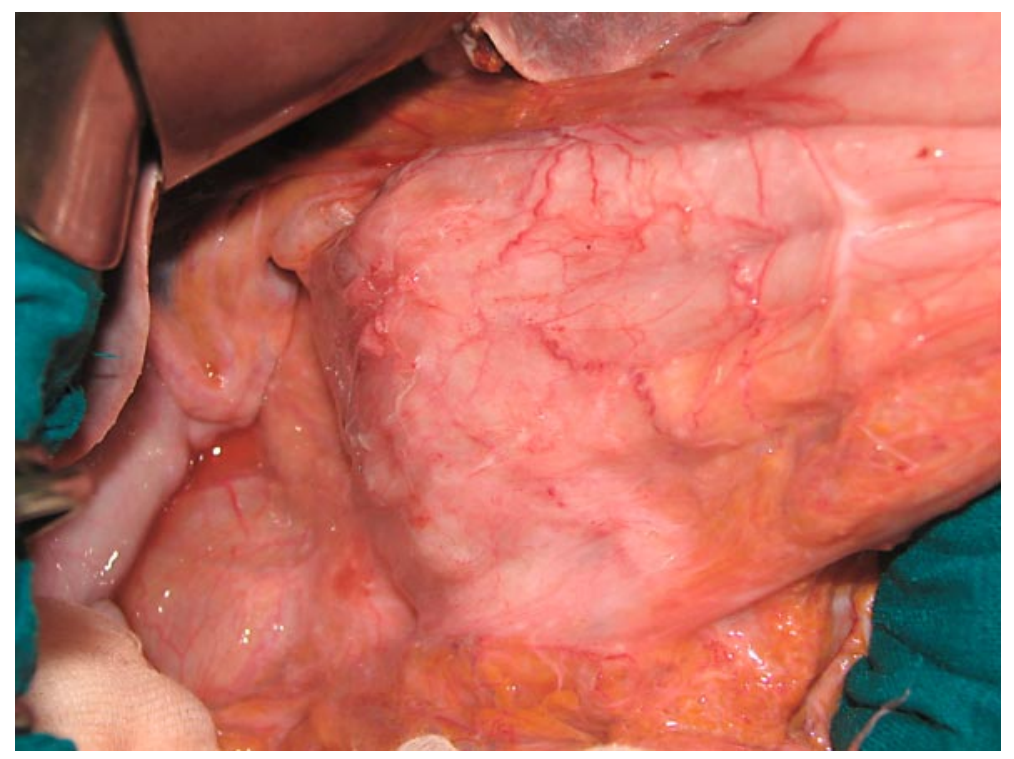




\begin{tabular}{r|l|l|l} 
Case Reports $/ \mathrm{n}$ & $\begin{array}{l}\text { Case Rep Gastroenterol 2008;2:444-450 } \\
\text { D0I: 10.1159/000161566 }\end{array}$ & Published online: November 15, 2008 & $\begin{array}{l}\text { I 2008 S. Karger AG, Basel } \\
\text { ISSN 1662-0631 } \\
\text { www.karger.com/crg }\end{array}$ \\
\hline
\end{tabular}

Fig. 3. CT scan showing regular thickening of the duodenal wall (D3).

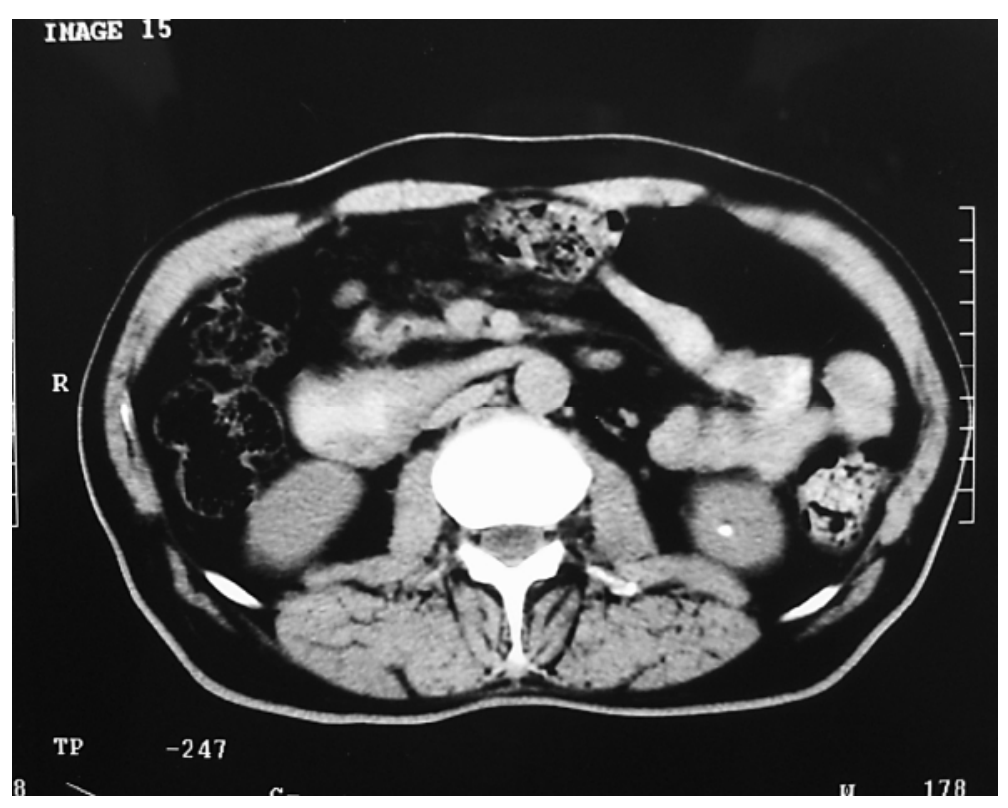

Fig. 4. Important dilation of the stomach on CT scan.

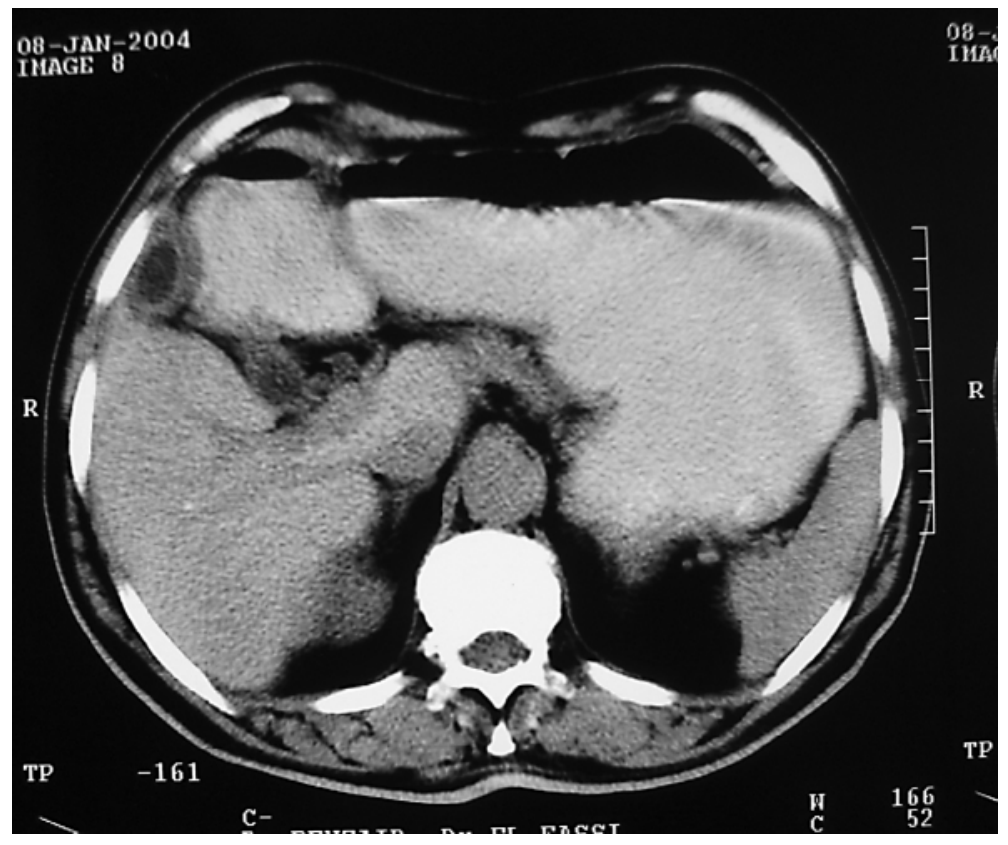




\begin{tabular}{r|l|l|l} 
Case Reports $/ \mathrm{h}$ & $\begin{array}{l}\text { Case Rep Gastroenterol 2008;2:444-450 } \\
\text { D0I: 10.1159/000161566 }\end{array}$ & Published online: November 15, 2008 & $\begin{array}{l}\text { O 2008 S. Karger AG, Basel } \\
\text { ISSN 1662-0631 } \\
\text { www.karger.com/crg }\end{array}$ \\
\hline
\end{tabular}

Fig. 5. Duodenal dilation (D2) secondary to duodenal stenosis (D3).

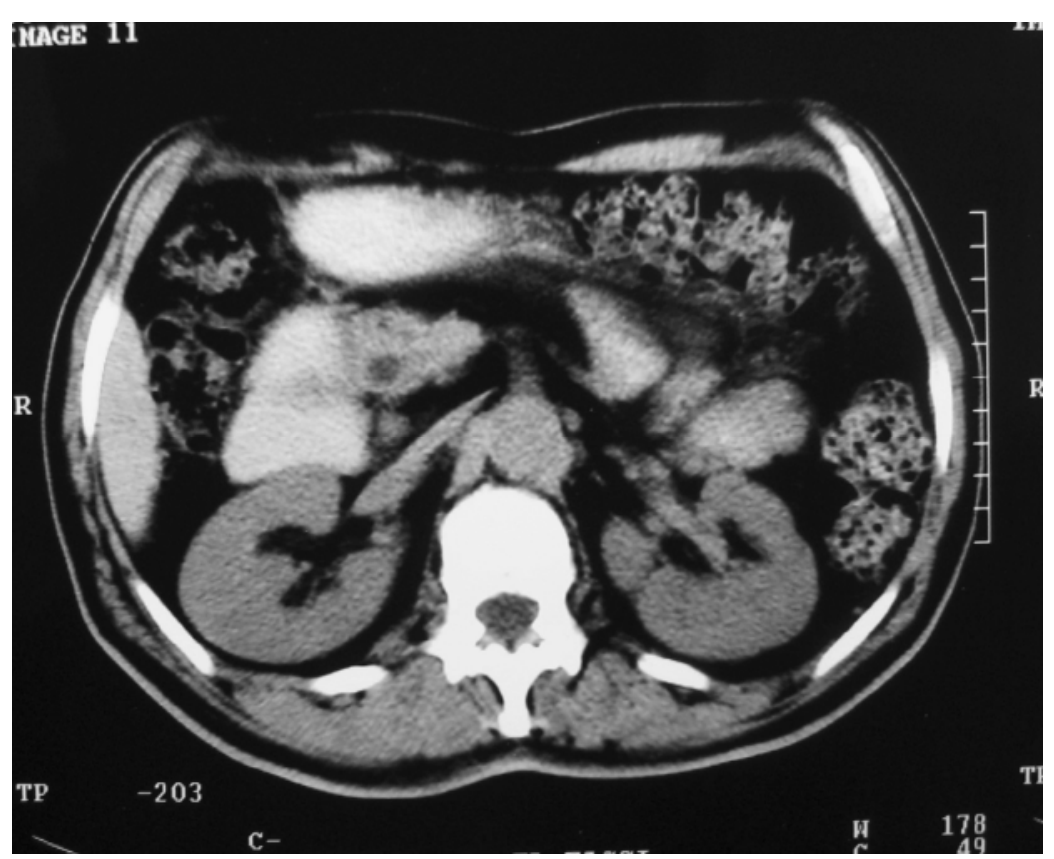




\section{References}

1 Dargan P, Sinha SK, Singh N, Jain BK, Shrivastava UK: Gastroduodenal tuberculosis: a report of three cases and review of literature. Internet J Gastroenterol 2005;4(1).

2 Rao YG, Pande GK, Sahni P, Chattopadhyay TK: Gastroduodenal tuberculosis management guidelines, based on a large experience and a review of the literature. Can J Surg 2004;47:364-368.

3 Padussis J, Loffredo B, McAneny D: Minimally invasive management of obstructive gastroduodenal tuberculosis. Am Surg 2005;71:698-700.

4 Vijayraghavan M, Arunabh, Sarda AK, Sharma AK, Chatterjee TK: Duodenal tuberculosis: a review of the clinicopathologic features and management of twelve cases. Jpn J Surg 1990;20:526-529.

5 Berney T, Badaoui E, Tötsch M, Mentha G, Morel P: Duodenal tuberculosis presenting as acute ulcer perforation. Am J Gastroenterol 1998;93:1989-1991.

6 Ali W, Sikora SS, Banerjee D, Kapoor VK, Saraswat VA, Saxena R, Kaushik SP: Gastroduodenal tuberculosis. Aust N Z J Surg 1993;63:466-467.

7 Lockwood CM, Forster PM, Forbes Catto JV, Stewart JS: A case of duodenal tuberculosis. Am J Dig Dis 1974;19:575-579.

8 Negi SS, Sachdev AK, Chaudhary A, Kumar N, Gondal R: Surgical management of obstructive gastroduodenal tuberculosis. Trop Gastroenterol 2003;24:39-41.

9 Raul SK, Das NA, Vakil R, Paljor YD, Joseph SC: Duodenal tuberculosis presenting as gastric outlet obstruction. Indian J Surg 2003;65:277-279. 